\title{
Utopioiden loppu Danila Tkatšenkon valokuvissa
}

Danila Tkatšenko (s. 1989 Moskovassa) on Venäjän tunnetuimpia uuden sukupolven valokuvaajia. Hänen läpimurtotyönään voidaan pitää mediakohun saattelemaa, vuonna 2017 julkaistua valokuvasarjaa Rodina (Isänmaa), jossa hän sytytti tuleen hylättyjä kyliä ja valo-

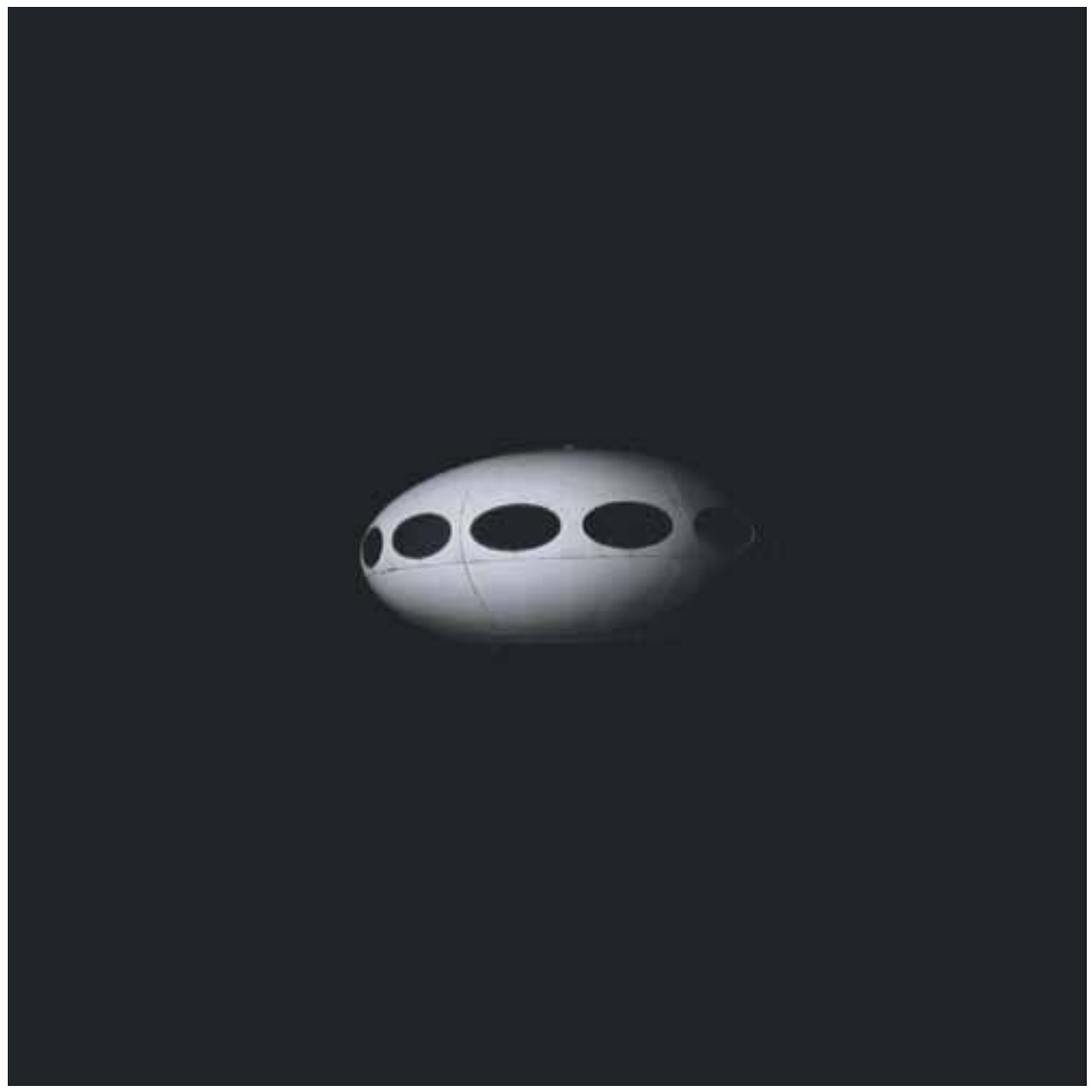

Futura-talo sarjasta Kadonnut horisontti, Dombai, Venäjä, 2016. 
kuvasi niitä. Hanke osui johonkin menneisyydestä tukea hakevan nyky-Venäjän kipupisteeseen ja jakoi mielipiteitä myös taidemaailmassa, vaikka oli tarkkaan harkittu eikä antanut aihetta esimerkiksi syytteille tuhopoltosta. Sen kuvaama radikaali irtiotto menneisyydestä on Tkatšenkon valokuville ominainen aihe. Historia, nostalgia ja muisti sekä näiden suhde nykyaikaan ovat hänen tähänastisen tuotantonsa kantavia teemoja, siinä missä venäläisen avantgarden perintökin. Yössä liekehtivä maalaistalokin voi muistuttaa Malevitšista modernistisen utopian loogisena lakipisteenä.

Usein Tkatšenkon valokuvissa käsitellään erilaisia moderneja menneisyyden sirpaleita, joita voi löytää ympäri Venäjää, aina Kaukasukselta löytyvästä Futura-talosta Pietarin avaruusmuseon Sputnikin pienoismalliin. Valokuvasarjassa Zakrytyje territorii (Suljetut alueet) sukelletaan eilispäivän teknisten vallankumousten ja modernisaation sivutuotteiden maisemiin, keskellä ei-mitään seisovien öljypumppujen ja hylättyjen parakkien maailmaan. Valokuvasarjassa Monumenty (Monumentit) Tkatšenko työskentelee suoraan historiallisen muistin alueella rinnastaessaan vallankumouksen jälkeen hylättyjä kirkkoja erilaisiin suprematistisiin abstrakteihin muotoihin, jotka hän on lavastanut kirkkojen yhteyteen. Useat

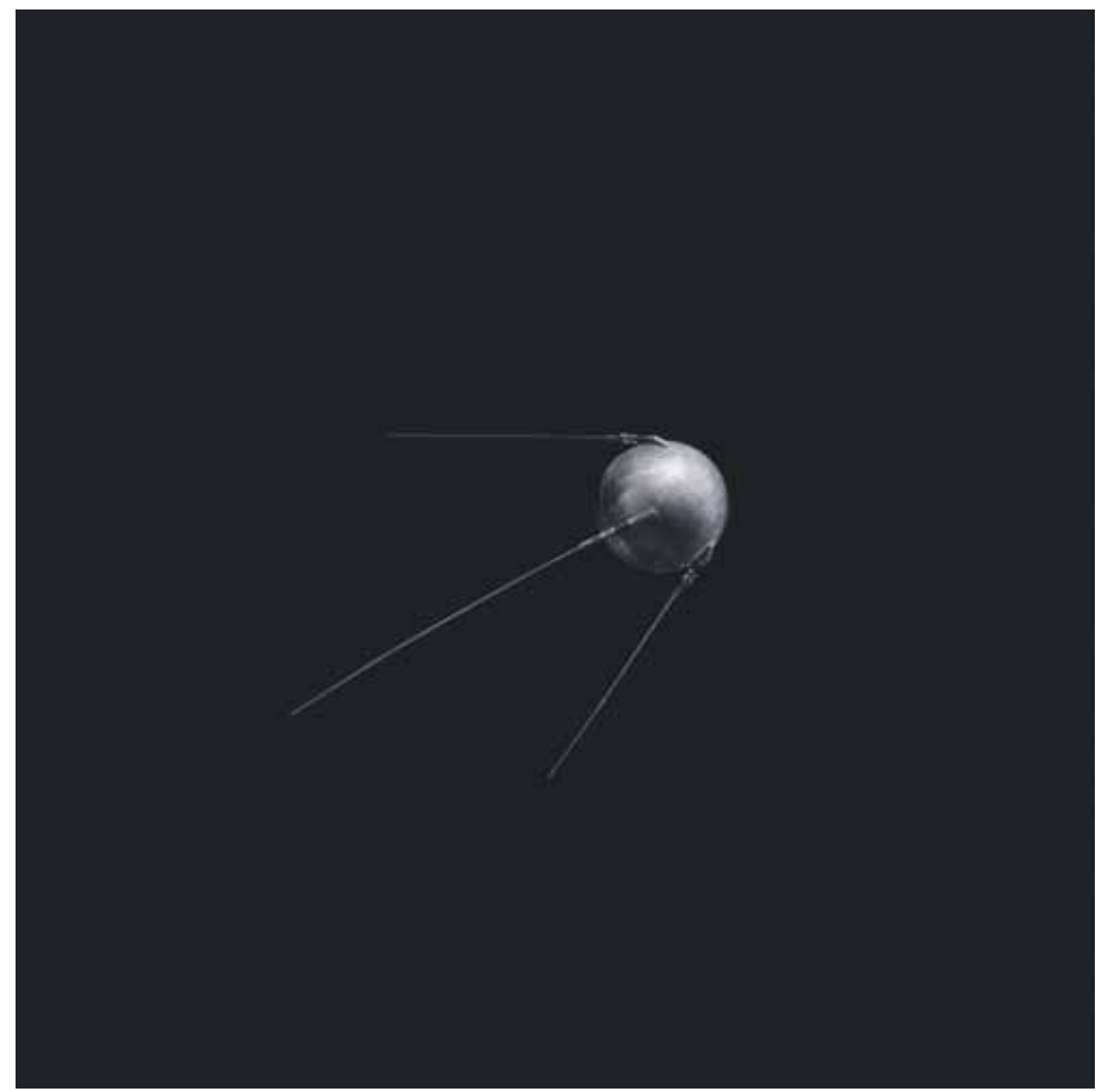

Sputnik-1:n pienoismalli sarjasta Kadonnut horisontti, Pietari, Venäjä, 2016. 
hänen valokuvasarjansa lähentelevätkin aktionismia, maataidetta, ja pyrkivät eroon valokuvan sisäänrakennetusta dokumentaarisuudesta.

Valokuvillaan Tkatšenko kommentoi yhtäältä Neuvostoliiton kaltaisia utopistisia projekteja kuin utopian raunioille noussutta nyky-Venäjää. Uusissa projekteissaan hän on etenevissä määrin kääntänyt katsettaan pois menneisyydestä kohti nykyaikaa.

Mika Pylsy

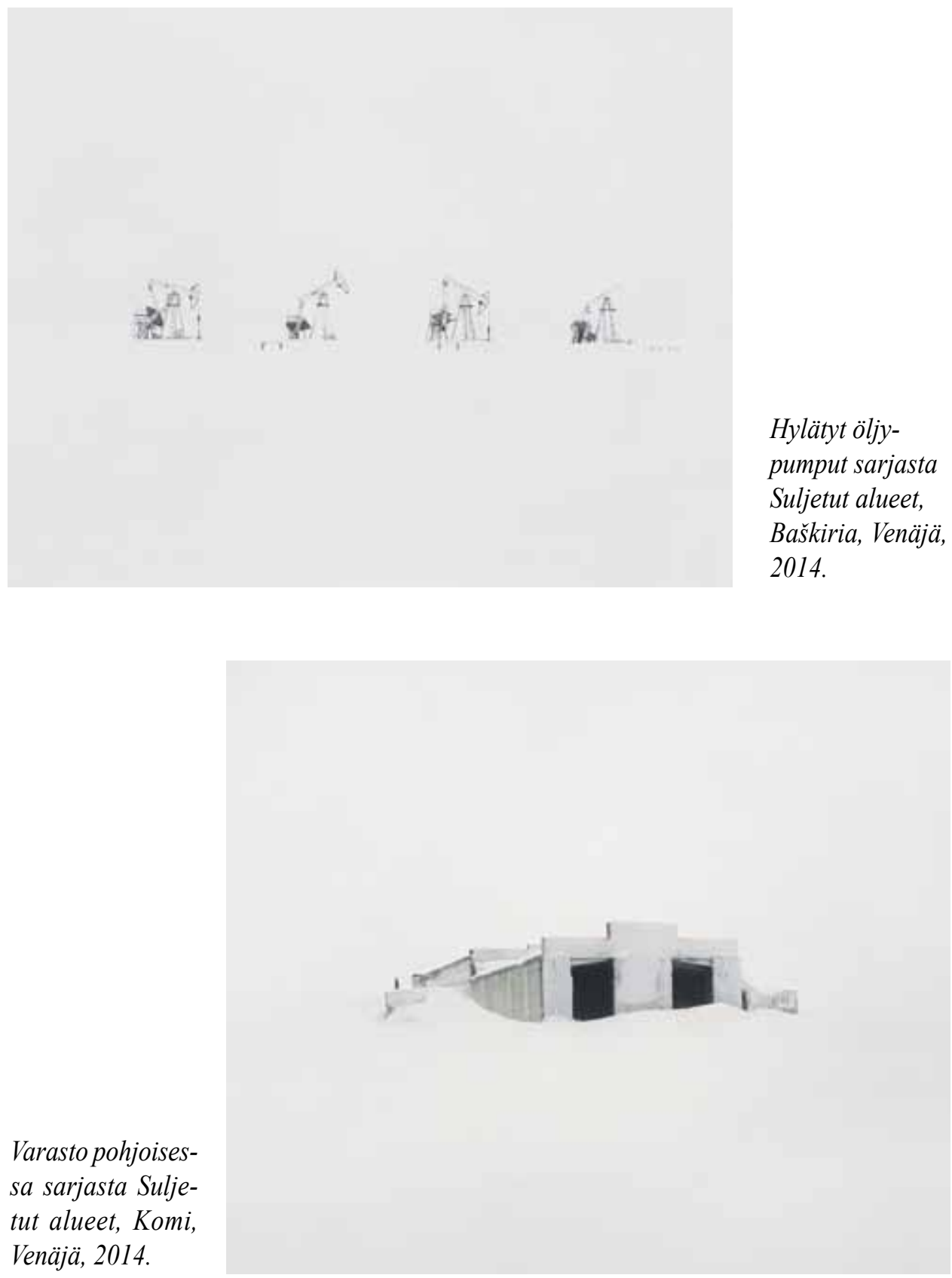




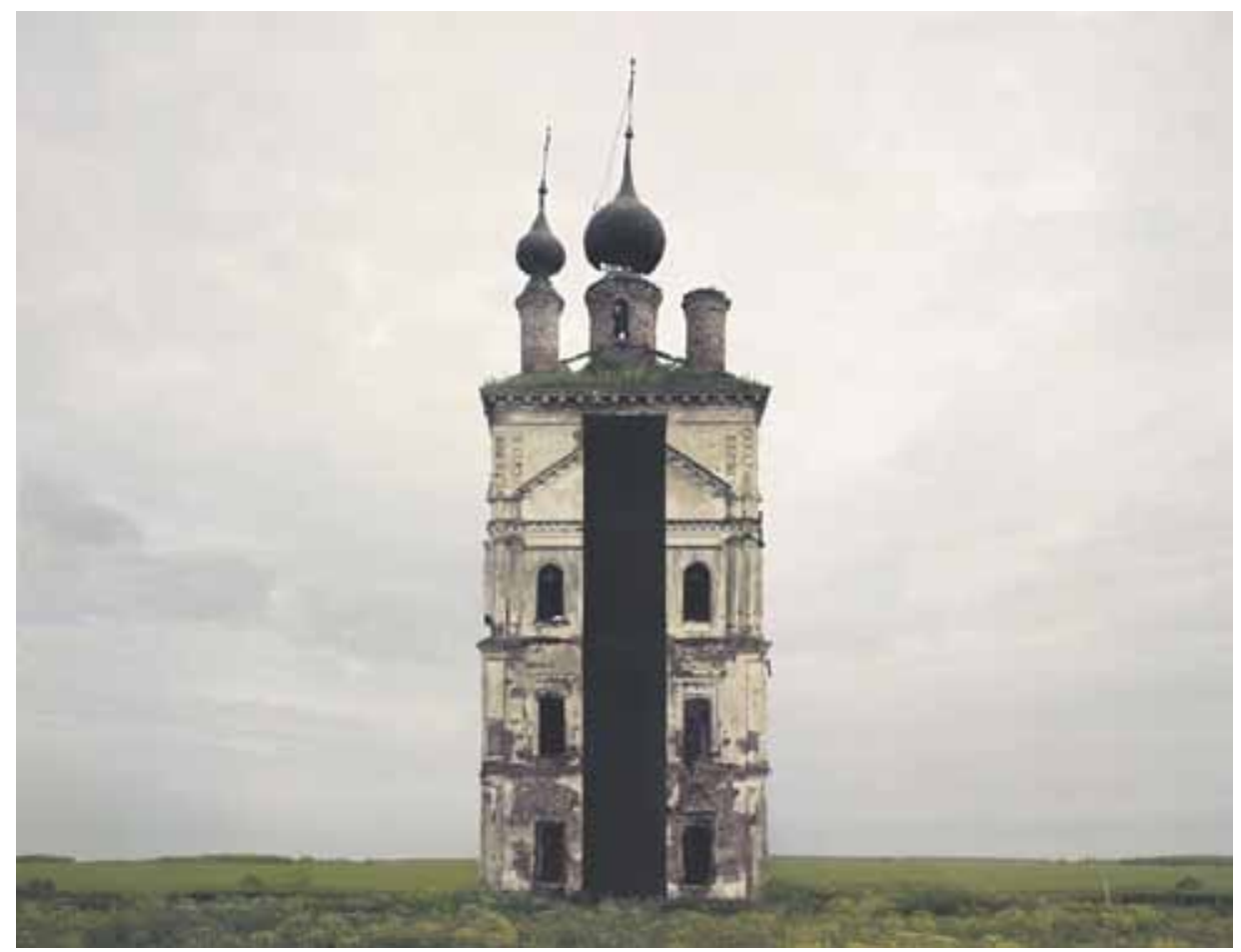

Valokuva 1 sarjasta Monumentit, 2017.

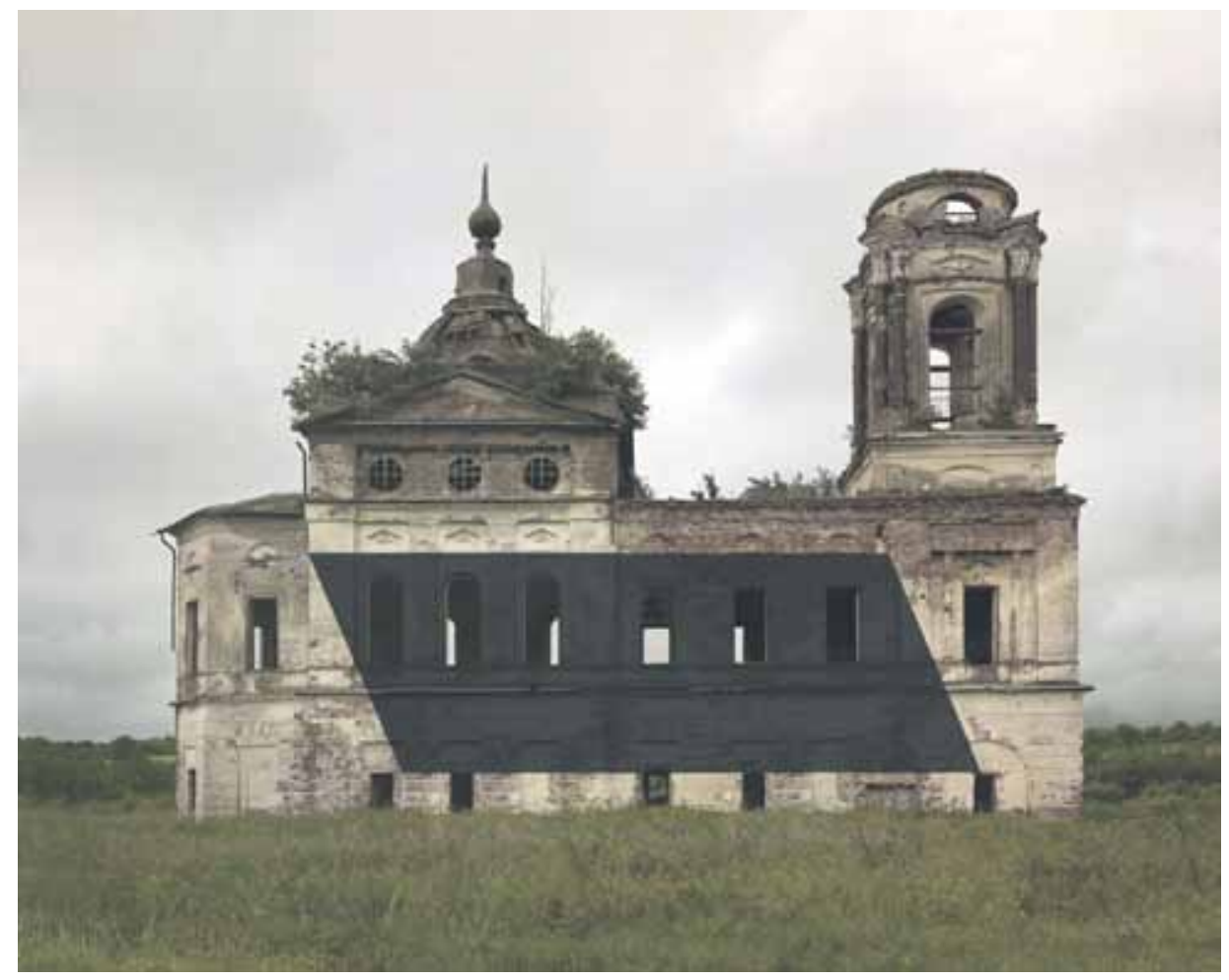

Valokuva 9 sarjasta Monumentit, 2017. 


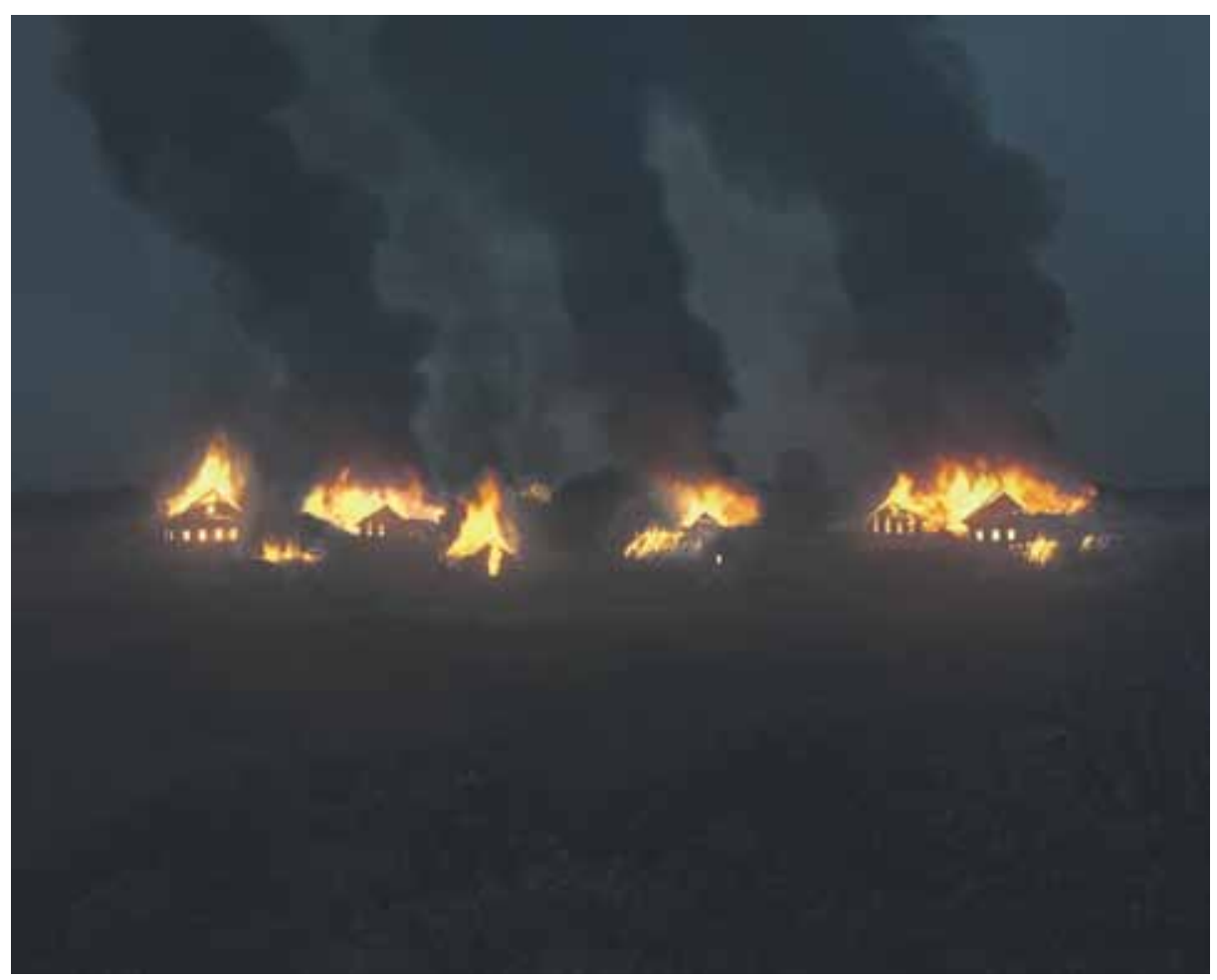

Valokuva 1 sarjasta Isänmaa, 2016.

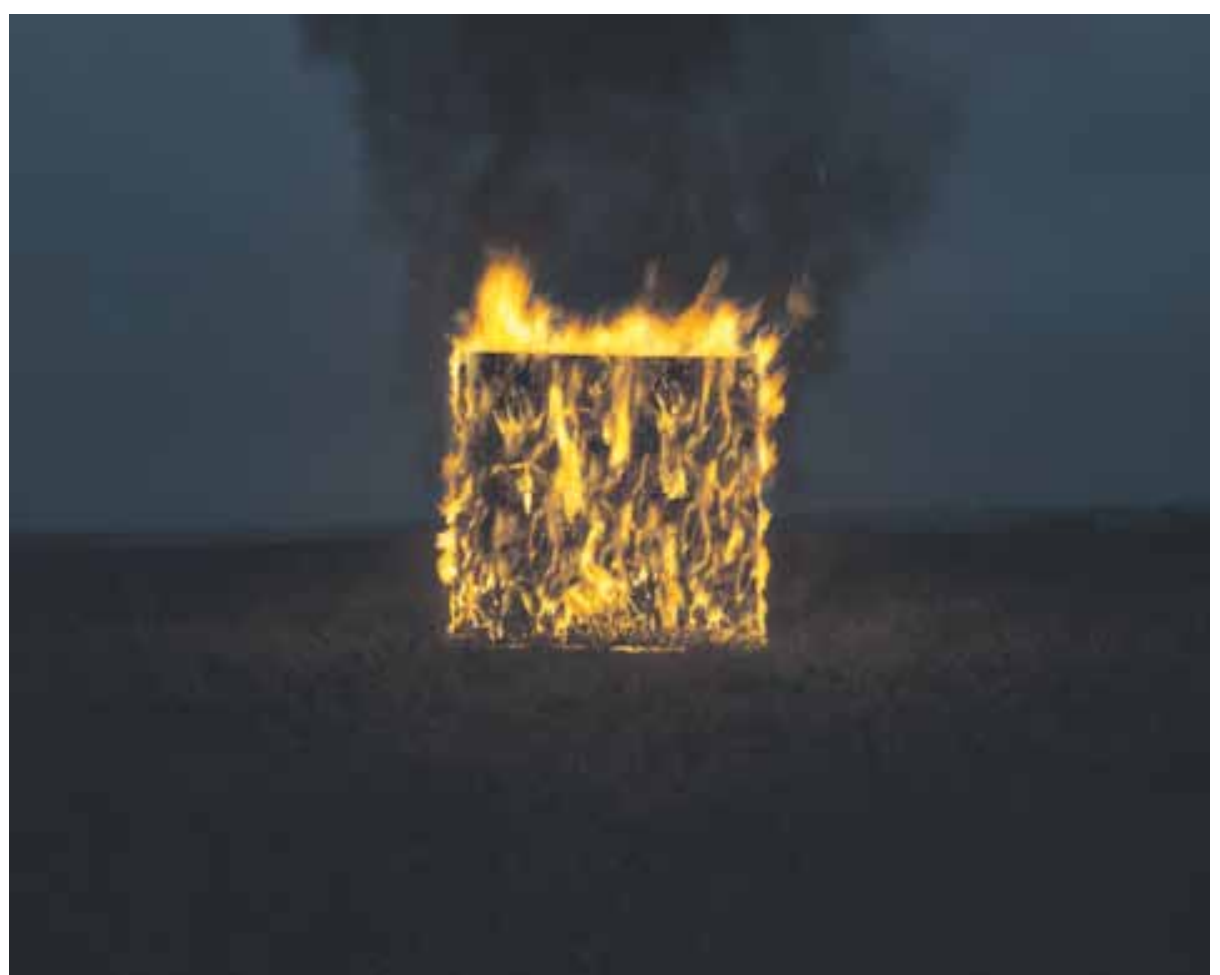

Valokuva 2 sarjasta Isänmaa, 2016.

78 IDÄNTUTKIMUS $1 / 2020$ 


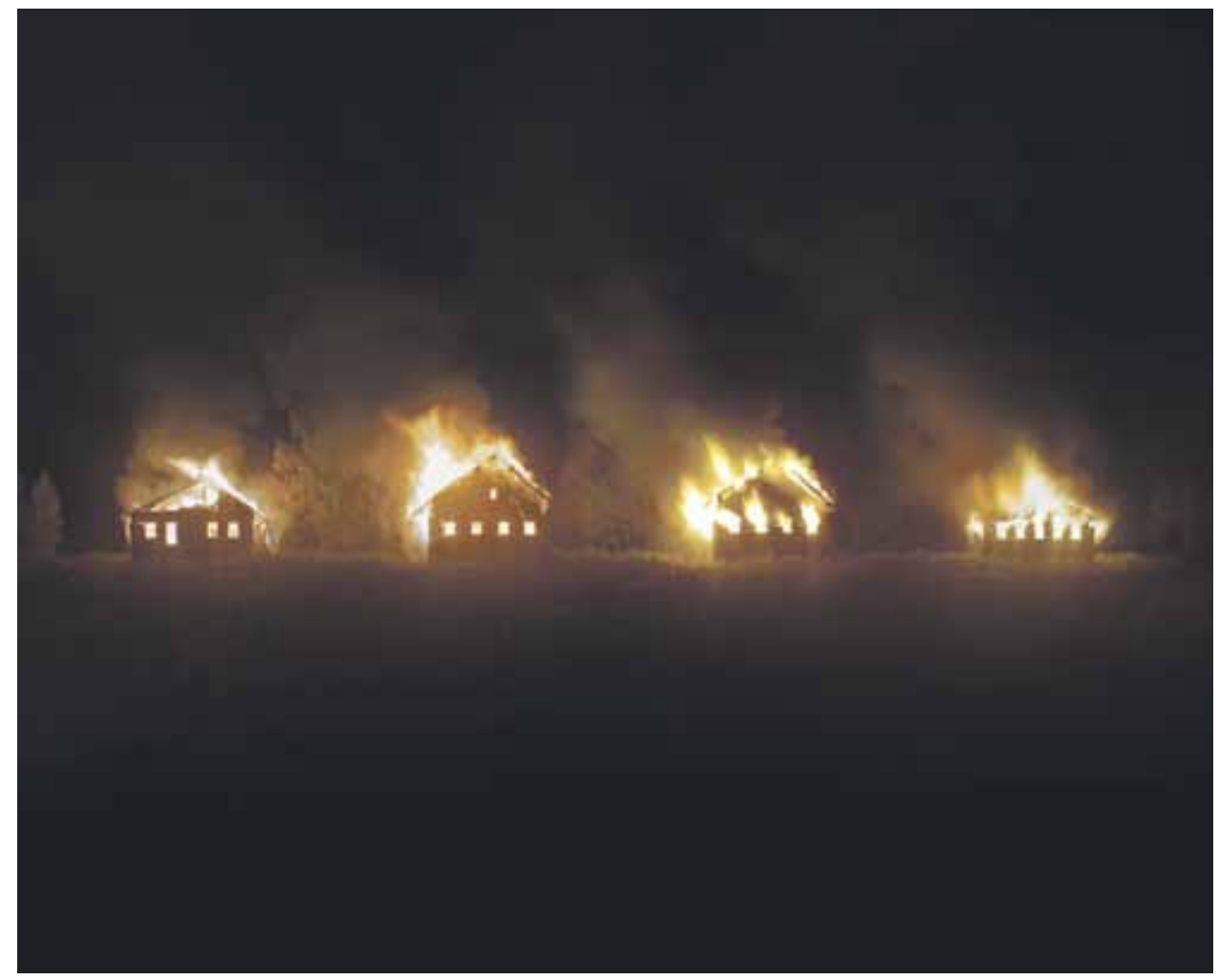

Valokuva 12 sarjasta Isänmaa, 2017. 